ISSN: 0213-3563

http://dx.doi.org/10.14201/azafea2019215576

\title{
LA ÉTICA ECOLÓGICA EN EL ANTROPOCENO
}

\author{
Ecological ethics in the Anthropocene
}

Manuel Arias Maldonado

Titular de Teoría Política en la Universidad de Málaga

Recibido: 20 de febrero de 2019

Aceptado: 19 de abril de 2019

\section{RESUMEN}

¿De qué manera afecta el Antropoceno a la ética ecológica? Sabido es que el primero no solo da cuenta de la formidable transformación de origen antropogénico experimentada por los sistemas planetarios, sino que de paso constata que el impacto humano sobre la Tierra es menos un accidente o contingencia que la consecuencia inevitable del modo de ser de la especie. Este artículo explorará las consecuencias que la actual emergencia planetaria tiene para la ética ecológica, arguyendo que la ausencia del sujeto político "humanidad" incrementa la importancia de un comportamiento individual que está, agregación mediante, en la raíz del cambio climático y demás manifestaciones del Antropoceno. Se defenderá la idea de que la virtud más importante para el ciudadano ecológico es la virtud epistémica de la reflexividad o autoconciencia, cuyo resultado habrá de ser la formación de una subjetividad planetaria orientada a la sostenibilidad e idealmente, a la reparación de las relaciones de la humanidad con el mundo natural.

Palabras clave: Antropoceno, ética ecológica, ciudadanía ecológica, humanidad, mundo natural, animals.

\section{ABSTRACT}

How does the Anthropocene impinges on environmental ethics? The former does not just attest to the extraordinary anthropogenic transformation experienced by planetary systems, but also certifies that human impacts on Earth are not accidents or contingencies but the unavoidable side-effect of 
our species' way of being. This article will explore the consequences that the current planetary emergency entail for environmental ethics, arguing that as humanity is not a political subject -or not yet-individual behavior acquires greater relevance -an individual behavior that once massively aggregated helps to create climate change and other Anthropocene-related problems. It will be defended that the key virtue for the ecological citizen is the epistemic virtue of reflexivity or self-awareness, the result of which should be the formation of planetary subjectivities oriented in turn towards sustainability as well as -ideally- the reparation of human relations with the natural world.

Key words: Anthropocene, environmental ethics, ecological citizenship, humanity, natural world, animals.

\section{INTRODUCCIÓN}

Pocos conceptos han irrumpido con tanta fuerza en el debate sobre las relaciones socionaturales como el de Antropoceno. A saber: la hipótesis según la cual el ser humano ha alterado los sistemas planetarios en tal medida que se ha convertido ella misma en una fuerza medioambiental global, con el correspondiente "acoplamiento" de los sistemas sociales y naturales ${ }^{1}$. Ya sea en su versión geológica, pendiente de ratificación oficial por parte de la Comisión Internacional de Estratigrafía, o en la proporcionada por la ciencia del sistema terrestre, el Antropoceno alude a un masivo cambio antropogénico del planeta ${ }^{2}$. No es que la idea de una "Era Humana” carezca de problemas: la postulación de conceptos alternativos como "Capitaloceno" o el "Oligopoceno" tiene por función cuestionar una atribución causal que identifica a la "humanidad" -sin matices- como responsable del de la disrupción planetaria en curso $^{3}$. Sin embargo, el concepto es capaz de acomodar esas críticas sin perder verosimilitud: describe una realidad factualmente verificable sin prescribir la interpretación que de ella deba hacerse. Ni el significado de la transformación antropogénica de la Tierra, ni la fijación de sus causas, ni las consecuencias normativas que de ahí deban deducirse están implícitas en el concepto: serán objeto -ya lo son- de discusión. A fin de cuentas, describir

1. Jianguo LiU, et al., "Complexity of Coupled Human and Natural Systems", Science, 317, 2007, p. 1513.

2. Erle C. Ellis, “Anthropocene: A Very Short Introduction”, Oxford University Press, Oxford, 2018.

3. Jason W. Moore (ed.), Anthropocene or Capitalocene? Nature, History, and the Crisis of Capitalism, PM Press, Oakland, 2016, p. 18. 
el estado contemporáneo de las relaciones socionaturales -o los efectos cuantificables del Antropoceno- no es suficiente. Para someterlo a evaluación moral y acción política no basta con saber qué ha pasado, sino averiguar por qué ha pasado. Solo de esta manera podremos diseñar normas morales y políticas públicas adaptadas a la nueva época.

¿Por qué hemos llegado hasta aquí? ¿Cómo explicar el impacto antropogénico sobre el medio natural? ¿Se trata de una contingencia histórica, una elección, algo que podría haber sido muy diferente? ¿O estamos más bien ante una necesidad humana universal, un destino al que no podemos escapar por razón del modo de ser de la especie? ¿De qué manera podemos prevenir los peores efectos del Antropoceno? ¿Cómo podemos ser sostenibles en un planeta climáticamente desestabilizado? ¿Y qué puede o debe hacer cada individuo al respecto? Así que la pregunta por el Antropoceno, es en primer lugar una pregunta por el ser humano: por el horizonte de posibilidades que se le presentan cuando se relaciona con el medio. Aunque sería más exacto hablar del medio natural tal como se le presenta en cada momento histórico. Las posibilidades no son infinitas, sino que están condicionadas por un horizonte que para el conjunto de los contemporáneos no parece sino estrecharse implacablemente.

Ahora bien, es imprescindible trascender aquí al individuo e introducir una perspectiva de especie. Al fin y al cabo, las acciones individuales no sirven por sí mismas para explicar la magnitud de la influencia humana acumulada en el tiempo: el Antropoceno es el producto de una agregación colosal. De ahí que, como señalan Dale Jamieson y Marcello di Paola, cada acción individual tenga dos vidas: una vida episódica de carácter privado y una vida sistémica de naturaleza colectiva ${ }^{4}$. Conducir un coche o tener un hijo parecen acciones irrelevantes, pero el tránsito diario de 1200 millones de vehículos o la producción alimentaria requerida para nutrir a 10.000.000 de personas ya es otra cosa. Tal como señala Virginie Maris, los seres humanos no son agentes geológicos; solo la humanidad en su conjunto puede serlo: ni individuos ni grupos pequeños tienen la capacidad para producir efectos sistémicos ${ }^{5}$.

4. Dale Jamieson y Marcello di Paola, "Political Theory for the Anthropocene", en David Held y Pietro Maffettone (eds.), Global Political Theory, Polity, Cambridge, 2016, pp. 254-280.

5. Virginie Maris, "Back to the Holocene. A conceptual, and possibly practical, return to a nature not intended for humans", en C. Hamilton et. al. (eds.), The Anthropocene and the Global Environmental Crisis, op. cit., 2015, pp. 123-133, p. 129. 
Esto, que puede parecer una obviedad, es de extraordinaria relevancia a la hora de preguntarnos por una ética para el Antropoceno; lo mismo cabe decir de la dimensión política del mismo. La razón es que la tradicional separación liberal entre una esfera privada (de cuyas acciones no habría que responder) y otra pública (que en cambio exige las debidas justificaciones) se ve seriamente cuestionada cuando las acciones privadas producen, una vez agregadas, efectos públicos de carácter sistémico. Es verdad que no lo hacen por igual: unos grupos sociales tienen mayor protagonismo que otros en la historia del impacto antropogénico sobre el planeta. No obstante, las novedades tecnológicas e institucionales se propagan entre las poblaciones y lo único que cuenta desde el punto de vista planetario es el efecto total de las acciones humanas y no la asignación intrahumana de responsabilidades. Se sigue de aquí que la corrección de los efectos indeseados de la influencia social sobre el planeta tendría como primera condición el desempeño conjunto de la humanidad: la agregación negativa del pasado demanda la agregación positiva del presente.

Este texto tiene por objeto reflexionar sobre la ética ecológica en el Antropoceno. O sea: sobre sus condiciones de posibilidad y sus contenidos bajo las nuevas condiciones creadas por la perturbación de los sistemas planetarios. Se estructura como sigue. En primer lugar, tras elucidarse en qué consiste la dimensión moral del Antropoceno, se planteará la pregunta acerca del sujeto político "humanidad" llamado a responder al Antropoceno ejerciendo como administradora del sistema terrestre. En segundo lugar, comprobado que ese sujeto no existe o en el mejor de los casos contiene una heterogeneidad que impide dar forma a una moralidad única, se propondrá una concepción de la ciudadanía ecológica que subraya su dimensión moral. A continuación, se discutirán las posibles virtudes del ciudadano ecológico en el Antropoceno. Finalmente, la discusión se desplazará del problema de la supervivencia humana a la cuestión de si, y cómo, hemos de reorganizar nuestras relaciones con las demás especies.

\section{LA HUMANIDAD COMO ADMINISTRADORA PLANETARIA}

¿Cuáles son las implicaciones morales y políticas que se deducen del Antropoceno? O sea, del estado de las relaciones socionaturales que nos describe la comunidad científica tras las pertinentes observaciones. En los últimos años se viene desarrollando un intenso debate sobre las implicaciones filosóficas, 
legales, estéticas, culturales y pedagógicas de la nueva época geológica entre los practicantes de las ciencias sociales y las humanidades. Se admite con ello, ya sea de manera explícita o implícita, la utilidad del concepto: el Antropoceno es un marco innovador que facilita pensar de otra manera en las relaciones entre humanidad y naturaleza ${ }^{6}$. Su premisa fundamental es que la acción humana es inherentemente transformadora y que la influencia antropogénica sobre el medio ambiente lleva produciéndose durante milenios.

Pero, ¿puede una época geológica, todavía oficiosa, ser interpretada moralmente? Todo indica que así es: si las acciones humanas pasadas han producido el Antropoceno, que es por tanto resultado de nuestras acciones y decisiones, lo que tenemos delante no es una noción extramoral. Máxime cuando, obligados como estamos ahora a vivir en el Antropoceno, serán las decisiones que adoptemos en las próximas décadas las que determinen -en buena medida- en qué Antropoceno viviremos ${ }^{7}$. Va de suyo que el debate sobre la sostenibilidad no es nuevo: precede a la datación del Antropoceno y siempre ha combinado la ciencia, política y moralidad. Lo que hace el Antropoceno es modificar la conversación, dando por sentado que hemos transformado el planeta y no podemos en consecuencia eludir nuestras responsabilidades: éstas se derivan del poder que, en gran medida sin darnos cuenta, hemos atesorado. Tomar conciencia de este hecho tiene así efectos morales:

Somos la primera generación con el conocimiento de cómo nuestras actividades influyen el sistema terrestre, y por lo tanto la primera generación que tiene el poder y la responsabilidad de cambiar nuestra relación con el planeta ${ }^{8}$.

La idea de que el ser humano haya de ejercer como "administrador" del mundo natural hunde sus raíces en la tradición occidental". Traducida al lenguaje del Antropoceno, implica una tarea de administración del sistema terrestre: más tecnócrata, en principio, que pastor. De otro modo, no podríamos hablar en esos términos; solo administra quien se sitúa en una posición de gobierno, no quien se retira y deja que la omisión produzca

6. Helmut Trischler, "Introduction", en H. Trischler (ed.), Anthropocene. Envisioning the Future of the Age of Humans, Rachel Carson Center Perspectives, 2013/3, pp. 5-8, p. 6.

7. Will Steffen et al., "The Anthropocene: From Global Change to Planetary Stewardship", Ambio, 40 (7), 2011, 739-761, p. 749.

8. Will Steffen et al., op. cit., 2011, p. 749.

9. John PASSMORE, La responsabilidad del hombre frente a la naturaleza. Ecología y tradiciones en Occidente, Alianza, Madrid, 1978, p. 27 
sus efectos. Sin embargo, la ambigüedad es inerradicable: que el ser humano se atribuya una función administradora nada dice acerca del modo en que esa función deba cumplirse. Por añadidura, la adopción de un enfoque tecnocrático sería en sí misma una decisión política, pues políticas son las respuestas a preguntas tales como qué aumento del nivel del mar es aceptable, qué especies habría que preservar, qué medios de transporte han de promoverse públicamente, qué grado de sufrimiento animal puede haber detrás de nuestra alimentación, qué equilibrio establecer entre emisiones y desigualdad, o si la geoingeniería del clima representa una opción tecnológica aceptable en una situación de emergencia. Puede alegarse, como ha hecho Isabelle Stengers, que la "intrusión de Gaia” complica el proyecto lineal y tecnocrático de la sostenibilidad al arrojarnos a un escenario impredecible donde la pura gestión resulta insuficiente ${ }^{10}$. El Antropoceno, que expresaría simultáneamente el creciente protagonismo geológico de la humanidad y su vulnerabilidad ante un planeta de violenta prehistoria, nos pone delante de un futuro lleno de ambivalencia e incertidumbre ${ }^{11}$. Por eso desborda el estudio científico y constituye una categoría política de nuevo orden. Tiene, además, un carácter ineludible:

The Anthropocene is not just something to be lamented and avoided as far as possible. Nor is it something good to be embraced, mastered, and celebrated. Rather, it is inescapable, and must be negotiated ${ }^{12}$.

Decíamos: si una humanidad unida se comprometiese sin ambages en el control de daños y la consecución de la sostenibilidad para el Antropoceno, todo sería más sencillo. Pero ese sujeto colectivo no existe; o no existe todavía. Puede alegarse que el demos global, a partir del cual podría articularse democráticamente una política para el Antropoceno, no ha sido reconocido aún por ninguna instancia oficial: incluso Naciones Unidas se asienta sobre los demos nacionales de los países que a ella pertenecen. Sin embargo, la maniobra por la cual la humanidad se percibe a sí misma como agente reflexivo encargado de administrar el sistema terrestre que ella ha perturbado antecede cualquier procedimiento democrático. Y, como ha escrito Peter

10. Isabelle Stengers, citada en Christophe Bonneuil y Jean-Baptiste Fressoz, The Shock of the Anthropocene, op. cit., 2013, p. 20.

11. Nigel Clark, "Geo-politics and the disaster of the Anthropocene", The Sociological Review, 62(S1), 2014, pp. 19-37, p. 25.

12. John S. Dryzer y Jonathan Pickering, The Politics of the Anthropocene, Oxford University Press, Oxford, 2019, p. 11. 
Sloterdijk, flota en el aire la pregunta de si la humanidad es capaz de asumir ese proyecto ${ }^{13}$.

¿Podría la humanidad, en fin, actuar como tal? ¿Será capaz de dar forma a un "nosotros" universal o a una voluntad general de índole socioecológica? A la vista de la fragmentación política de las democracias liberales, ese ambicioso propósito parece más improbable que nunca. Pero podríamos dar la vuelta a esa dificultad: la lucha contra la insostenibilidad, que es también el proyecto de dar forma a un "buen Antropoceno", podría suministrar a esas democracias el motivo unificador del que hace tiempo vienen careciendo ${ }^{14}$. El Antropoceno podría suponer así el regreso de los grandes relatos que la posmodernidad había enterrado:

El fracaso del relato moderno sobre una humanidad universal unida en torno a un proyecto común no implica que no pueda nunca haber una historia que aglutina a toda la humanidad. ¿Acaso la llegada del Antropoceno no proporciona nuevo fundamento para una narrativa humana unitaria? ${ }^{15}$.

Acabada la Guerra Fría de unos contra otros, empezaría la Guerra Caliente de todos contra el planeta. Así razona justamente Bruno Latour, para quien la unidad del sujeto "humanidad" debe asentarse sobre el descubrimiento de que esa guerra está en marcha: si no entramos en combate, Gaia acabará con nosotros ${ }^{16}$. Ahora mismo, la humanidad no está unida aunque parezca estarlo: la verdadera unidad necesita de la convicción de que estamos ante un peligro existencial que no admite faccionalismos. Una vez que el riesgo climático se haga visible de manera incontestable, la habitual rivalidad entre grupos humanos será sustituida por la unión de todos los grupos humanos contra un enemigo inhumano. Jeremy Davies es más modesto: será la transición del Holoceno al Antropoceno, visible en su turbadora riqueza de episodios climáticos extremos, la que vaya creando un sentimiento colectivo

13. Peter Sloterdijk, Was geschah im 20 Jahrbundert?, Suhrkamp, Berlín, 2017, p. 13.

14. Sobre el "buen Antropoceno" y la controversia asociada al acento ecomodernista del concepto, véase Manuel Arias-Maldonado, “Towards a Good Anthropocene?”, en Manuel Arias-Maldonado y Zev Trachtenberg (eds.), Rethinking the Environment for the Anthropocene. Political Theory and Socionatural Relations in the New Geological Age, Routledge, Londres, 2019, pp. 137-150.

15. Clive Hamilton, Defiant Earth. The Fate of Humans in the Anthropocene, Polity, Cambridge, 2017, p. 77.

16. Bruno Latour, Facing Gaia: Eight Lectures on the New Climatic Regime, Polity Press, Cambridge, 2017. 
entre las generaciones de humanos que habitan las fisuras que se abren entre las dos épocas geológicas ${ }^{17}$.

Pero, ¿no será también una ficción esperar que una humanidad consciente por fin de la necesidad de actuar en el frente ecológico será una humanidad capaz de ponerse de acuerdo sobre el plan a seguir? Por más exitoso que sea a la hora de persuadir a las distintas generaciones de humanos de la necesidad de tomarse el Antropoceno en serio, ningún ejercicio de "demogénesis" producirá por sí solo el consenso necesario a tal fin. Ya se ha sugerido antes que, como señala una de las críticas más repetidas al concepto de Antropoceno, el anthropos es una realidad múltiple cuyos miembros no han contribuido ni contribuyen de igual manera al impacto antropogénico sobre el planeta ${ }^{18}$. Pero es que lo mismo puede decirse sobre sus intereses, valores y preferencias: que son diversos y con frecuencia incompatibles. Así que una hipotética humanidad soberana es tan plural como el pueblo soberano de cualquier democracia constitucional. He aquí una de las razones por las cuales no se ha logrado de momento identificar ningún proceso que pueda aglutinar a los seres humanos de todo el mundo y convierta la solidaridad ecológica en una fuerza política ${ }^{19}$.

Acaso sea sorprendente que la peligrosidad extrema del Antropoceno no baste para unir a la humanidad. Lo cierto -y esta es otra razón que lo explicaes que no terminamos de creer que la supervivencia esté en juego. Pero, aunque así fuese, no hay una sola manera de sobrevivir: según cuáles sean los valores a cuya realización damos prioridad, el Antropoceno puede adoptar distintas formas. Para unos, será necesario acabar con el capitalismo; otros alegarán que las fuerzas de mercado, debidamente encauzadas, son las únicas capaces de proporcionar la innovación necesaria; y aún habrá quien alegue que el crecimiento económico de los países pobres es más importante que atenuar el calentamiento. Y con todo, la humanidad necesita empezar reconociendo la existencia de un problema descomunal que exige toda su atención. Una vez se haya logrado este acuerdo previo, podrá discutirse acerca de medios y fines.

Ninguna política del Antropoceno, pues, resulta viable sin la previa unificación política de la especie. Este acto fundacional de la geo-política podría

17. Jeremy Davies, The Birth of the Anthropocene, University of California Press, Oakland, 2016, p. 148.

18. Véanse Andreas Malm y Alf Hornborg, "The geology of mankind? A critique of the Anthropocene narrative", The Anthropocene Review, 1, 2014, pp. 62-69

19. Benjamin Kunkel, "The Capitalocene”, Londres Review of Books, 39(5), 2 marzo 2017, pp. 22-28. 
llevarse a cabo, al decir de algunos, mediante una reelaboración del contrato social. Es sabido que las teorías contractuales clásicas razonaban en términos puramente antropocéntricos y excluían al mundo natural; ahora se trataría de incorporarlo. Para Michel Serres, pionero en la demanda de este neocontractualismo, debemos añadir al contrato exclusivamente social un contrato natural de simbiosis y reciprocidad que reconozca el equilibrio entre el poder humano y las fuerzas del planeta ${ }^{20}$. Los defensores de un contrato socionatural vienen así a decir que no necesitamos herramientas nuevas, sino que es suficiente con con adaptar las existentes: la noción ilustrada de progreso moral sería extendida al mundo no humano, al tiempo que se extiende el ideal cosmopolita para llegar hasta las futuras generaciones de humanos ${ }^{21}$. Parte fundamental de este nuevo contrato global sería el reconocimiento de una ciudadanía ecológica que incorpore deberes y obligaciones individuales hacia el planeta. No hablamos entonces de ciudadanos globales sino terrestres. Reformulando la queja conservadora contra el cosmopolitismo, nunca estamos en ninguna parte y siempre estamos en alguna parte, o sea, estableciendo relaciones materiales con un planeta que reacciona a nuestra presencia. Esta reacción no es siempre dócil o amistosa y conviene tenerlo presente: la desestabilización planetaria que distingue a la nueva época geológica insinúa que tal vez no haya al otro lado de la mesa ninguna entidad dispuesta a "firmar" contrato alguno. Clive Hamilton encabeza el pelotón de los escépticos:

Hablar ahora de un segundo contrato -un acuerdo de reciprocidad y justicia entre la humanidad y la naturaleza- proyecta una concepción de la sociedad propia del siglo XVII sobre la Tierra del Antropoceno -un mundo social de leyes, tratados, obligaciones y sanciones, de derechos y responsabilidades, impuestas sobre una entidad que no sabe nada de asuntos asi ${ }^{22}$.

No obstante, Hamilton pide demasiado: el contrato es otra ficción, un instrumento por el cual la humanidad reconoce la necesidad de abordar de manera decidida el problema del Antropoceno. Es un marco, no un reglamento. Hasta tanto esta monumental maniobra de autorreconocimiento no

20. Michel Serres, The Natural Contract, The University of Michigan Press, Ann Arbor, 1995, p. 44

21. Byron Williston,The Anthropocene Project. Virtue in the Age of Climate Change, Oxford University Press, Oxford, p. 22.

22. Clive Hamilton, "Human Destiny in the Anthropocene", en C. Hamilton et al. (eds.), op. cit., The Anthropocene and the Global Environmental Crisis. Rethinking Modernity in a New Epoch, Routledge, Abingdon, 2015, pp. 32-43., p. 39. 
tenga lugar, con todo, seguiremos como estamos: combinando una gobernanza internacional de orientación tecnocrática y un debate público mayormente especializado donde se discute la forma que un "buen Antropoceno" habría de adoptar.

\section{De la subjetividad planetaria al ciudadano antropocénico}

Estamos viviendo una época excepcional: por primera vez en su historia, el ser humano es consciente de su capacidad para alterar las condiciones de vida planetarias. Esto es especialmente cierto en lo que al clima se refiere, a pesar de que su perturbación antropogénica ha sido en gran medida involuntaria y -hasta hace poco- inconsciente. Bruno Latour habla de un "nuevo régimen climático" para resumir una situación en la que el contexto biofísico que los ciudadanos de la modernidad dábamos por supuesto se ha vuelto inestable y ejerce presión sobre la especie: "como si el decorado hubiera entrado en escena para compartir el drama con los actores ${ }^{23}$. Sobre la gravedad de la situación, en definitiva, no caben dudas. ¿Qué hacer?

Vaya por delante que para las corrientes más pesimistas hablar de una ética para el Antropoceno es una incongruencia. La escala del problema al que nos enfrentamos es tan monstruosa que las normas morales no le serían aplicables. Más aún: emplear un lenguaje moral para hablar del Antropoceno puede hacer que lo normalicemos, como si se tratase de un problemas medioambiental ordinario. Es la posición de Clive Hamilton:

Hablar de ética es banalizar una transición que pertenece al tiempo profundo y supone literalmente una sacudida planetaria. En el tiempo profundo, no hay ética ${ }^{24}$.

Se trata de una tesis atractiva, que sin embargo conduce a un callejón sin salida. Es indudable que la desestabilización planetaria conducirá algún día a la desaparición de la especie humana; tal vez cuando se produzca la próxima glaciación. Su inquietud es, pues, comprensible: no deberíamos pensar que ahorrando agua o compartiendo coche resolveremos una crisis planetaria.

23. Bruno Latour, Facing Gaia, op. cit., 2017, p. 3.

24. Clive Hamilton, Christoph Bonneuil, François Gemenne, “Thinking the Anthropocene", en C. Hamilton et al. (eds.), The Antbropocene and the Global Environmental Crisis. Rethinking Modernity in a New Epoch, Routledge, Abingdon, 2015, pp. 1-13, p. 8 . 
Este derrotismo puede verse agravado por el contraste entre el tipo de fenómeno que el Antropoceno es y la capacidad de influencia que sobre él tiene cada uno de nosotros. Ya que si no cambian aquellas infraestructuras globales -de la energía al transporte- de las que dependemos para nuestras actividades cotidianas, ¿qué impacto puede tener una acción individual? Para colmo, estamos mal equipados para comprender las consecuencias remotas -o sistémicas- de nuestras decisiones; algo nada sorprendente cuando lo que tenemos delante es temporal y espacialmente tan vasto que nos resulta difícil sentir urgencia ${ }^{25}$.

Ya hemos comprobado que el Antropoceno es una consecuencia de la agregación de conductas individuales a una escala masiva: nuestras acciones tienen una vida episódica asociada a nuestra esfera privada y una vida sistémica que produce efectos públicos. Esta dimensión sistémica se activa cuando nuestra conducta individual entra en contacto con la infraestructura del Antropoceno: el sistema energético global, el sistema alimentario global, el sistema de transporte global. Sus efectos se agregan entonces al resto, de manera sostenida y acumulativa, produciendo efectos de especie. En consecuencia, hablar de una ética para el Antropoceno supone forzosamente la problematización de la divisoria entre lo público y lo privado. Se trata de una separación típicamente liberal, lo que plantea de inmediato un problema: si la desestabilización planetaria fuese de hecho un efecto colateral del ejercicio de la libertad individual que ocupa el centro normativo del liberalismo político, ¿pueden aplicar las sociedades liberales unas políticas que parecen contradecir los principios que las fundan? Dale Jamieson es claro:

¿Es sostenible una sociedad que permite un alto grado de libertad personal e individualismo cuando los horizontes materiales empiezan a achicarse y los sistemas ecológicos se desordenan ${ }^{26}$.

A decir verdad, nadie destruye el mundo natural ni desestabiliza los sistemas planetarios de manera intencionada: individuos y sociedades transforman el planeta mientras persiguen otros objetivos. Pero el efecto no depende de la

25. Véanse Dale Jamieson, Reason in a Dark Time, op. cit., 2014, p. 180; Samantha Frost, "Challenging the Human X Environment Framework", en T. Gabrielson et al. (eds.), The Oxford Handbook of Environmental Political Theory, op. cit., 2016, pp. 178-192, p. 186.

26. Dale Jameson, Reason in a Dark Time. Why the Struggle Against Climate Change Failed -and What it Means for our Future, Oxford University Press, Oxford, 2014, p. 224. 
intención; y es del efecto lo que nos concierne. La cuestión es que conductas consideradas tradicionalmente como privadas -desde ducharse a comer una hamburguesa- tienen ahora consecuencias públicas, pues contribuyen a la disrupción de unos sistemas planetarios de los que depende la vida de todos. Esto significa que perjudican también a sujetos que no han tomado parte en esas acciones: las generaciones futuras, otras sociedades, las demás especies. Es un efecto acumulativo: debido a las complejas mediaciones que caracterizan a nuestros sistemas sociales, ni mi ducha ni mi hamburguesa pueden considerarse causa del cambio climático y otras alteraciones sistémicas. Pero mis emisiones se agregan a las emisiones de los demás, dispersándose en una intrincada cadena causal que incluye deslizamientos espacio-temporales: el dióxido de carbono enviado hoy a la atmósfera provoca el calentamiento del futuro. Ocurre que las teorías morales tradicionales sufren en ausencia de intencionalidad (requisito de los enfoques deontológicos) y cadenas causales lineales (requeridas por los enfoques consecuencialistas) ${ }^{27}$. Ningún individuo es, aisladamente considerado, responsable de la desestabilización de los sistemas planetarios; ninguno puede tampoco resolver en solitario los problemas así creados.

¿De qué manera puede romperse este círculo vicioso? ¿Puede restringirse la libertad individual en nombre de la sostenibilidad colectiva? Sabemos lo que piensan al respecto los decrecentistas, poco preocupados por el debilitamiento de los principios liberales -autonomía individual, pluralismo social- que podría traer consigo un disciplinamiento a gran escala orientado a desmantelar a la fuerza el sistema capitalista mundial. Pero también hay pensadores liberales que consideran justificado, en determinadas circunstancias, imponer límites públicos a las preferencias privadas. La razón es sencilla: el ejercicio de la libertad es imposible si arruinamos las condiciones de las que ese ejercicio depende. Y es que ningún derecho, ni siquiera ése, es ilimitado. Se deduce de aquí que las conductas privadas pueden ser sometidas a escrutinio público.

Ahora bien, me interesa aquí menos hablar de coacción legal que de moralidad. Sobre el papel, no es necesario que el poder público imponga nuevos estándares -por ejemplo prohibiendo los automóviles con motor de combustión- para que esos estándares cambien; si no masivamente, si en una proporción significativa. Acciones como ducharse prolongadamente o dejar una luz encendida no son explícitamente políticas, pero tienen consecuencias políticas. Por esa razón, los cambios en los estilos de vida poseen una

27. Marcello Di Paola, "Virtues for the Anthropocene", Environmental Values, 24(2), 2015, pp. 183-207. 
dimensión política: son una señal para los legisladores y un modo de influir en otros conciudadanos ${ }^{28}$. Pero nada sería más eficaz en el plano individual que la generalización de algún tipo de ética antropocénica, o sea, de un modo de estar en el mundo que reflejase la conciencia de que ese mundo debe ser habitable. Eso, claro, no sucederá mientras no se generalice una subjetividad planetaria que podemos definir como propia del ciudadano consciente de vivir en el Antropoceno y de las responsabilidades que ello comporta.

En mi interpretación del concepto, el núcleo de la ciudadanía ecológica está constituido por la libre asunción de valores o guías de acción que, orientándose hacia la sostenibilidad, vayan más allá de lo exigido por las leyes vigentes $^{29}$. Si todos los ciudadanos sin excepción están obligados al cumplimiento de éstas, la diferencia la marcará el ciudadano que haga más de lo que se le exige. No es necesario prefijar el contenido de esa contribución: puede adoptar un estilo de vida sostenible, entablar una relación más cuidadosa con el mundo natural, reducir su huella ecológica o su consumo de combustibles fósiles, votar a partidos ecologistas o animalistas, o comprar en función de los estándares asumidos con las empresas. Tampoco es obligado militar contra el capitalismo, ni dejar de comer carne: basta con que el individuo tome conciencia de la necesidad de avanzar hacia alguna modalidad de la sostenibilidad medioambiental y señalice esa preferencia a través de su conducta o de sus hábitos. Este ciudadano ecológico será también un ciudadano antropocénico, aunque si bien se mira a esta última categoría pertenece todo aquel que venga habitando el planeta desde hace medio siglo: el Antropoceno trasciende regímenes políticos y fronteras para abarcar al conjunto de la humanidad viva.

\section{Virtudes morales para el Antropoceno.}

Pues bien, ¿de qué manera debería obrar un individuo que haya tomado conciencia del problema climático que condiciona el presente y futuro de las comunidades humanas? Hay que empezar por señalar que la pluralidad del anthropos y la ambivalencia de las relaciones socionaturales a gran escala hacen imposible definir una moral única para el Antropoceno. Salvo, claro está,

28. Stijn Neuteleers, "Institutions versus lifestyle: do citizens have environmental duties in their private spheres?”, Environmental Politics, 19 (4), 2010, pp. 501-517.

29. Véase Manuel Arias-Maldonado, Real Green. Sustainability after the End of Nature, Ashgate, Farnham, 2012. 
que reduzcamos sus mandamientos a uno solo de carácter genérico o abstracto, del tipo "harás todo lo posible para reducir el impacto antropogénico negativo sobre el planeta". El adjetivo es importante, porque también existen impactos antropogénicos positivos; por ejemplo, aquellos que tienen que ver con la reparación de ecosistemas dañados. Por otra parte, la idea de una moralidad única no encaja bien con una sociedad liberal donde la ley no prescribe a los individuos cómo deben vivir. Y por mucho que el imperativo de la sostenibilidad prime sobre el ejercicio irrestricto de la libertad individual, el cambio social necesario para asegurar la habitabilidad del planeta -no digamos ya para dar forma a un "buen Antropoceno"- parece requerir el consentimiento de los ciudadanos si aspira a ser eficaz. Por último, la moralidad única choca con la búsqueda de soluciones para la insostenibilidad, díficil de alcanzar sin el concurso de las mejores ideas disponibles y, por tanto, fuera de un contexto donde éstas -también en el mercado- puedan intercambiarse y experimentarse libremente.

Podemos, en todo caso, definir una ética de mínimos para el Antropoceno. Y hacerlo, o tratar de hacerlo, identificando las virtudes que debería poner en práctica un ciudadano ecológico. Dale Jamieson ha sugerido que el individuo ha de cultivar ciertas disposiciones y emociones que le motiven para reducir las emisiones de $\mathrm{CO}_{2}$ en sus distintos avatares -consumidores, ciudadanos, padres- sea cual sea el comportamiento de los demás. Esas virtudes no son demasiado novedosas: humildad, templanza, cooperatividad, conciencia, respeto por la naturaleza. Para Jamieson, esta última es la más importante, pues debería conducir espontáneamente hacia las demás. Y ello porque supone que quien respeta el mundo natural hará lo necesario para conservarlo o protegerlo ${ }^{30}$. Sin embargo, es dudoso que así sea. Es posible respetar o apreciar el mundo natural y seguir tomando duchas largas; se trata de una virtud parcial de la que no deducen necesariamente las demás.

Mi tesis es que la virtud moral más importante para el ciudadano ecológico en el Antropoceno es eso que Jamieson llama "conciencia" [awareness]. Hablamos de la capacidad reflexiva que nos hace conscientes de las implicaciones de nuestra conducta en el marco de las relaciones socionaturales y, por tanto, de sus potenciales consecuencias para los sistemas planetarios. La mayor parte de las conductas medioambientalmente dañinas son irreflexivas e inerciales: hacemos lo que veníamos haciendo y vemos que hacen los demás. En palabras de Di Paola, hay que hacer justamente lo contrario:

30. Dale Jamieson, Reason in a Dark Time, op. cit., 2014, p. 186. 
El agente reflexivo se esfuerza por ubicar sus comportamientos dentro de la infraestructura global, reconstruyendo las premisas causales y anticipando las implicaciones de un paseo ocioso en coche o de la oferta de fruta importada desde otro continente ${ }^{31}$.

Estamos así ante una virtud epistémica (nos permite comprender mejor la realidad) y afectiva (nos impele a hacer algo para cambiarla) de la que habrán de derivarse las demás: ya sean la templanza, la cooperatividad o el respeto. Al fin y al cabo, todas ellas pueden entenderse como el efecto que produce un proceso de toma de conciencia. De ahí brotan también las subjetividades planetarias, que son asimismo ejercicios de reflexividad. Su origen puede estar en algún acontecimiento particular, como una ola de calor o una temporada de huracanes, pero también ser un desarrollo más sutil o influido por la opinión del grupo social de pertenencia.

Ocurre que Jamieson parece presuponer una respuesta determinada al problema de la insostenibilidad. Su ciudadano virtuoso semeja un decrecentista franciscano que aboga por la terminación del capitalismo y el regreso a formas comunitarias de vida. Sin embargo, esto no es estrictamente necesario: la ciudadanía antropocénica será tan plural como la ciudadanía liberal. El sujeto que se hace cargo del problema de la habitabilidad planetaria no tiene por qué decantarse por la solución más tajante. Pero no solo puede preferir alguna modalidad de reformismo, como por ejemplo el representado por la tradición de la modernización ecológica; también podría confiar en la innovación tecnológica o en la capacidad resolutoria de unos mercados diseñados de la manera adecuada. Lo importante es que se haga la pregunta acerca de la estabilidad futura de los sistemas planetarios, sistema climático incluido; decidir de antemano cómo haya de responderla supone restringir el pluralismo democrático. También es precipitado: la tarea más urgente es producir ciudadanos ecológicos en una sociedad en la que no abundan. Una vez que ese objetivo se haya logrado, cabe esperar que la aplicación de políticas sostenibles dirigidas a estabilizar el Antropoceno será mucho más sencilla.

\section{Más allá de la supervivencia: el mundo no humano EN EL ANTROPOCENO}

La emergencia climática ha acentuado un rasgo problemático de la sostenibilidad medioambiental: su inclinación a la desviación antropocéntrica. $\mathrm{O}$,

31. Marcello Di Paola, "Virtues for the Anthropocene”, op. cit., 2016, p. 199. 
si se prefiere, la facilidad con la que desatendemos a otras especies mientras atendemos a la continuidad de la nuestra. A ello puede contribuir el exacerbado sentimiento de «urgencia» que asociamos con un momento socionatural que nos pone delante el horizonte de la extinción e incluso nos urge a pensar en un escenario post-apocalíptico ${ }^{32}$. Si de lo que se trata de asegurar no es la sostenibilidad sino la supervivencia, pues en un planeta sobrecalentado ni siquiera tendríamos la oportunidad de ser insostenibles, el mundo no humano puede quedar aún más fuera de foco o contemplado solo desde el punto de vista instrumental: apreciado solo como proveedor de servicios o suministrador de recursos. De ahí que, por el contrario, la reflexión sobre un "buen Antropoceno" que vaya más allá de la supervicencia deba forzosamente incorporar una reflexión moral acerca del modo en que el ser humano deba relacionarse con el mundo natural.

Pero, ¿de qué manera conseguir que los seres humanos entablen una nueva relación con el mundo natural en el Antropoceno? Puede alegarse que se requiere ante todo un nuevo modo de ver, capaz de prestar mayor atención a las demás especies y a sus condiciones de florecimiento. Para ello, quizá sea preferible atender menos a la Naturaleza en abstracto que a sus manifestaciones particulares. Y no se hace con ello referencia únicamente a los animales, que cuentan con la ventaja que proporciona su cualidad viva y por ello interactiva. Detrás del concepto de Naturaleza encontramos una realidad multiforme que incluye a los mares, las selvas, los desiertos e incluso las bacterias; una mutiplicidad que implica también una densa red de relaciones e interdependencias de la que formamos parte. Jane Bennett, con su propuesta de una "ecología política de las cosas" ha tratado de avanzar en esta dirección, aludiendo a una "materialidad vibrante" que nos descubre una ontología común ${ }^{33}$. Va de suyo que el horizonte final de un ecologismo emancipador se nos presenta hoy en día bajo un aspecto inequívocamente utópico, pues difícilmente puede calificarse de otra manera el propósito de liberar al mundo natural de toda dominación humana. Mick Smith ha recurrido al concepto de soberanía para describir -en su caso refiriéndose como ejemplo a las ballenas- este exigente mandato moral:

32. Véanse Amanda H. Lynch y Siri Veland, Urgency in the Anthropocene, The MIT Press, Cambridge y Londres, 2018, y Richard Grusin (ed.), After Extinction, University of Minnesota Press, Minneapolis y Londres, 2018.

33. Véase Jane Bennett, Vibrant Matter. A Political Ecology of Things, Duke University Press, Durham y Londres, 2010. 
Salvar las ballenas es liberarlas de toda demanda de soberanía humana, dejarlas en su singularidad, en su ser tal como es -cualquiera que sea-quodlibet ens, en los flujos del tiempo evolutivo, de la historia natural, igual que ellas se dejan ser en los flujos de los océanos del planeta. Este acto de 'salvación' es una acción ético-política ${ }^{34}$.

Por desgracia, es imposible que la especie humana habite el planeta sin transformarlo ni dañar con ello a otros seres vivos: a veces directamente y otras privándoles del hábitat que necesitan para subsistir. Pero la imposibilidad de evitar todo daño no autoriza a inflingir cualquier daño. Y solo abriendo los ojos a las formas más cotidianas de dominación y crueldad es posible empezar a remediarlas: desde el uso recreativo de calesas urbanas al enjaulamiento de pájaros, pasando por el consumo de terneros o corderos lechales y la pervivencia de espectáculos circenses que incorporan animales. Podemos mencionar también el cambio en el tratamiento jurídico de los grandes simios y otros mamíferos que, según se apilan las pruebas científicas que certifican su cognición, obtienen un mayor reconocimiento y protección. Ni que decir tiene que la especial cercanía evolutiva de los grandes simios o el espontáneo cariño que sentimos por los llamados "animales carismáticos" facilita estos avances. En España, por ejemplo, hemos visto cómo un pleno reciente del parlamento revocaba un artículo del Código Civil que otorgaba a los animales domésticos la condición de "cosas" e incoporaba la hoy extendida definición de los mismos como "seres sintientes".

Ahora bien, el Antropoceno no deja de crear ciertos problemas a la justificación teórica de ese propósito emancipador. Tomemos, por ejemplo, la fórmula propuesta por David Schlosberg: aplicar al mundo no humano la teoría de las capacidades formulada por Amartya Sen y Martha Nussbaum, de acuerdo con la cual todo ser humano tiene derecho a disfrutar de un conjunto de capacidades básicas sobre la base de su igual dignidad ${ }^{35}$. Este esquema podría aplicarse no solo a los animales, sino a entidades naturales como los ríos o los ecosistemas; todos ellos tendrían derecho a "realizarse" conforme a su "naturaleza". El atributo decisivo no sería la dignidad, sino la integridad;

34. Mick Smith, Against Ecological Sovereignity. Ethics, Biopolitics, and Saving the Natural World, University of Minnesota Press, Minneapolis y Londres, 2011, p. 103.

35. David Schlosberg, "Ecological Justice for the Anthropocene”, en M. W IssenBurg y D. Schlosberg (eds.), Political Animals and Animal Politics, Palgrave, Houndmills, 2014, pp. 75-89; Amartya SEN, Commodities and Capabilities, Oxford University Press, Oxford, 1999; Martha Nussbaum, Women and Human Development: The Capabilities Approach, Oxford University Press, Oxford, 2000. 
hacer justicia medioambiental será respetar la integridad de los seres y las entidades no humanas: no podrá detenerse el río, ni horadarse la montaña, ni destruirse el ecosistema.

Ahora bien, ¿podemos seguir hablando de “integridad” en un Antropoceno que nos señala el formidable grado de hibridación que han alcanzado las relaciones socionaturales? Si hay que entender la integridad como ausencia de intervención humana, su aplicación se antoja dificultosa; el consenso necesario no parece fácil de obtener. Surgen no pocas preguntas: ¿es obligado que todos los ríos del planeta lleguen al mar sin ser detenidos? ¿Cómo podríamos generar energía hidráulica o abastecernos de agua potable? ¿Cuándo se viola la integridad de un ecosistema? ¿Y la de un árbol o una planta? ¿Deben los seres humanos abstenerse de cualquier acción que pueda dañar o afectar al mundo no humano? ¿Y de restaurar ecosistemas o recuperar especies en riesgo de extinción?

Tal como ha insistido el filósofo Steven Vogel, el ser humano es un agente "perturbador" para el mundo no humano; lo es con su sola presencia, que no puede dejar de ser destructiva y transformadora a partes iguales. No podemos seguir pensando en los términos del viejo Aldo Leopold cuando establecía una oposición excluyente entre comunidad humana y comunidad biótica $^{36}$. La cualidad "natural” de un ecosistema o ser vivo no es una categoría absoluta, sino un grado que depende de la cantidad y calidad de la influencia antropogénica ejercida sobre él. En ese sentido, incluso hablar de conservación de una naturaleza "natural" plantea considerables dificultades. Puede que todavía exista una naturaleza más o menos intacta, pero su proporción sobre el total es exigua. Emma Marris ha señalado que si bien la naturaleza está en casi todas partes, en casi ninguna parte es prístina ya ${ }^{37}$. La idea del wilderness -el sublime espacio natural al que cantaron los románticos primero y los trascendentalistas norteamericanos más tarde- ha modelado en buena medida nuestra concepción de la naturaleza: será natural aquello que esté separado del ser humano. Para salvar la naturaleza tendríamos, entonces, que distanciarnos de ella. Pero, ¿tiene esto sentido en la era posnatural? ¿No se hace necesario cambiar nuestra mirada sobre la naturaleza, dejando de identificar la naturaleza con el Edén perdido?

36. Aldo Leopold, A Sand County Almanac. And Sketches Here and There, Oxford University Press, Oxford, 1987, pp. 224-225.

37. Emma Marris, Rambunctious Garden. Saving Nature in a Post-Wild World, Bloomsbury, Nueva York, 2011, p. 56. 
Es cierto que semejante planteamiento sugiere no pocos problemas de orden publicitario: si queremos proteger lo natural, defender la idea de que lo natural ya no existe quizá no sea la mejor estrategia persuasiva. No es que la idea contraria haya funcionado demasiado bien. Invocar la integridad del mundo natural en el Antropoceno podría entenderse así como una suerte de anacronismo constructivo, que podría servirnos para hacernos ver que el planeta está lleno de seres y hábitats vulnerables hacia los que podemos desarrollar nuevas disposiciones morales. Puede ser un modo, artificioso si se quiere, de conservar el asombro [wonder] que para Andrea Wulf podría ligarnos afectivamente con el mundo no humano ${ }^{38}$.

Se hace aquí patente otra paradoja del Antropoceno, y es que los mismos que están obligados a educarse en la fragilidad de los sistemas planetarios habitan unas ciudades donde no solemos reconocer la presencia del mundo natural. Asimismo, el conservacionismo ha centrado sus esfuerzos en la protección de la naturaleza salvaje, dando a los habitantes de los espacios urbanos y suburbanos la impresión de que no hay mundo natural donde ellos viven. Aunque nada más lejos de la realidad: la naturaleza mundana que encontramos en los centros urbanos incluye a las mascotas, la vegetación urbana y doméstica, una variada fauna que vive en los intersticios urbanos, recursos como el agua, el aire y la comida. Será en el vecindario y no en la granja donde los urbanitas del siglo XXI habrán de encontrar retazos del mundo natural, pues es en estos paisajes híbridos donde pasamos la mayor parte de nuestras vidas ${ }^{39}$. Meditando acerca de su jardín londinense, Tom Chatfield se ha preguntado:

¿Estoy más cerca de la naturaleza? ¿Es la naturaleza una especie de activo, como la proximidad a un buen colegio o a la estación? No. La naturaleza es el paquete completo: la casa y el jardín, la ciudad y el campo. Es la única garantía de nuestra existencia, la única esquina del universo conocido que es hospitalaria para la vida ${ }^{40}$.

38. Andrea Wulf, "In awe of nature", New Philosopher, 14, noviembre 2016, pp. 77-79.

39. Damien White y Chris Wilbert, "Inhabiting Technonatural Time/Spaces”, en D. White y C. Wilbert (eds.), Technonatures. Environments, Technologies, Spaces, and Places in the Twenty-first Century, Wilfried Laurie University Press, Waterloo, 2009, pp. 1-30, p. 4.

40. Tom Chatrield, “The new human era”, New Philosopher, 14, noviembre 2016, pp. 41-42, p. 41. Steve Hinchliffe, Geographies of nature. Societies, Environments, Ecologies, Sage, Londres, 2007, p. 165. 
Por añadidura, el proceso de concentración poblacional en núcleos urbanos facilita la creación de reservas naturales que -debidamente conectadas por corredores que permitan la circulación de especies- deben contribuir a la regeneración de los sistemas planetarios. También es sabido que las ciudades están llamadas a erigirse en actores principales de las políticas climáticas. Diane Ackerman dibuja un futuro esperanzador en el que, biomímesis mediante, las ciudades y los espacios públicos se conviertan en

organismos vivos que limpiarán el aire de agentes contaminantes, incrementarán su oxígeno, reducirán el ruido, ahorrarán energía, refrescarán nuestro espíritu y nos enraizarán más hondamente en el mundo natural ${ }^{41}$.

A ese fin pueden ayudar también los "espacios para la naturaleza” que propone Steve Hinchliffe. O sea, lugares y prácticas que nos ayuden a comprender nuestra co-dependencia, co-evolución y diferencias respecto al mundo no humano ${ }^{42}$. Hinchliffe no es explícito, pero podemos incluir dentro de las mismas aquellas iniciativas públicas o privadas que fomenten una mejor comprensión de las relaciones socionaturales: diseñar parques urbanos, crear reservas naturales, desarrollar estrategias turísticas ligadas a la conservación, facilitar la presencia de las mascotas en el espacio público, incentivar los huertos urbanos y las azoteas ajardinadas, organizar tours educativos para los colegios o paneles de información sobre el cambio climático y sus amenazas. Son propuestas bienintencionadas cuya realización solo será posible gracias a una vigorosa voluntad pública o a una robusta sociedad civil.

En suma, el mundo natural no ocupa un lugar en el Antropoceno, sino muchos. Hay una naturaleza inhumana de orden geológico que amenaza nuestra supervivencia, igual que hay sistemas naturales tan determinantes para nuestra vida cotidiana como el climático. Pero también están la naturaleza salvaje, la naturaleza mundana escondida en las ciudades, la naturaleza doméstica que nos acompaña en el interior de nuestros hogares. Incluso hay una naturaleza "nacional": buena parte de la literatura naturalista es también una celebración del suelo patriótico y sus distintas manifestaciones animales o paisajísticas, pese a que el mundo natural -como es obvio- no conoce fronteras ${ }^{43}$.

41. Diane Ackerman, The Human Age. The World Shaped by Us, W W. Norton \& Company, Nueva York \& Londres, 2014, p. 83.

42. Steve Hinchliffe, Geographies of nature, op. cit., 2007, p. 165.

43. Richard Sмyтh, "How British Is It?", Times Literary Supplement, 17 mayo 2017. 
En última instancia, no hay necesidad de resolver teóricamente el problema de la naturaleza ni de encontrar una razón que nos obligue a protegerla; basta con que aseguremos en la práctica una protección suficiente de la mis$\mathrm{ma}^{44}$. No importa qué valor defienda cada cual si hay unidad de propósito: una sostenibilidad que incorpore un refinamiento de las relaciones que mantenemos con otras especies. Y sin embargo, el Antropoceno proporciona una importante razón adicional para procurar el cuidado del mundo natural. La transformación humana del planeta ha alterado las condiciones de vida de las demás especies y eso comporta un deber de tutela por parte del ser humano. La naturaleza superficial que componen los ecosistemas y las demás especies han perdido su vieja soberanía: se encuentran tan indefensos ante nosotros como nosotros ante la desestabilización planetaria.

\section{Conclusión}

Este artículo se ha dedicado a la pregunta sobre la ética en el Antropoceno. Una pregunta que también es un problema, pues el deterioro de los sistemas planetarios de los que da cuenta la ciencia exige una respuesta colectiva que asegure la habitabilidad del planeta. Y aunque esa respuesta habrá de ser forzosamente concertada, hablar de ética nos obliga a pensar en el individuo y, más concretamente, en el individuo que decide hacer más de lo que le exigen las leyes vigentes; de otro modo, confundiríamos el respeto a la legalidad con las virtudes morales. Esto es especialmente importante a la vista de que, como se ha señalado más arriba, el sujeto político "humanidad" no existe aún y, si llegara a constituirse de manera eficaz, no dejaría de estar atravesado por múltiples diferencias interiores. Si hubiera un solo modo de alcanzar la sostenibilidad, o asegurar la habitabilidad, cabría imaginar un alineamiento general de los ciudadanos en torno a esa política o conjunto de políticas. Pero no es el caso: tenemos el fin, pero debatimos sobre los medios en un contexto de incertidumbre y cambio constante. Bajo esas condiciones, las decisiones individuales cobran importancia. Y la tesis que aquí se ha defendido es que la virtud más importante para el ciudadano ecológico en el Antropoceno no es exactamente una virtud moral, sino una virtud epistémica: la virtud de la autoconciencia planetaria. Solo quien da forma a una subjetividad planetaria podrá desarrollar otras virtudes morales, como el respeto o la humildad o

44. Erle ElLIS, "Nature for the people. Toward a democratic vision for the biosphere”, Breakthrough Journal, 7, 2017. 
el cuidado. Esta voluntad de cuidado derivada de la conciencia planetaria adquiere especial relevancia cuando trascendemos el estrecho marco de la supervivencia humana y nos preocupamos por dar forma a un «buen Antropoceno» donde se reconsideran las relaciones del ser humano con las demás especies. La consiguiente desactivación de la máquina antropológica, por parcial que sea, topa con especiales condiciones en un Antropoceno que desdibuja la frontera entre el mundo humano y el no humano. En último término, solo la reparación de unas relaciones marcadas ahora mismo por la explotación animal y el deterioro antropogénico de la biosfera lograrán evitar un final infeliz que convierta al planeta en un escenario post-humano $\mathrm{y}$, calentamiento progresivo mediante, post-animal. 